\title{
The impact of PMSE and NLC particles on VLF propagation
}

\author{
D. Nunn ${ }^{1}$, M. A. Clilverd ${ }^{2}$, C. J. Rodger ${ }^{3}$, and N. R. Thomson ${ }^{3}$ \\ ${ }^{1}$ Dept. of Electronics and Computer Science, Southampton University, Southampton SO17 1BJ, UK \\ ${ }^{2}$ British Antarctic Survey, Cambridge, CB3 OET, UK \\ ${ }^{3}$ Dept. of Physics, University of Otago, Dunedin, New Zealand
}

Received: 4 August 2003 - Revised: 6 January 2004 - Accepted: 14 January 2004 - Published: 8 April 2004

\begin{abstract}
PMSE or Polar Mesosphere Summer Echoes are a well-known phenomenon in the summer northern polar regions, in which anomalous VHF/UHF radar echoes are returned from heights $\sim 85 \mathrm{~km}$. Noctilucent clouds and electron density biteouts are two phenomena that sometimes occur together with PMSE. Electron density biteouts are electron density depletion layers of up to $90 \%$, which may be several kms thick. Using the NOSC Modefndr code based on Wait's modal theory for subionospheric propagation, we calculate the shifts in received VLF amplitude and phase that occur as a result of electron density biteouts. The code assumes a homogeneous background ionosphere and a homogeneous biteout layer along the Great Circle Path (GCP) corridor, for transmitter receiver path lengths in the range of $500-6000 \mathrm{~km}$.
\end{abstract}

For profiles during the $10 \mathrm{~h}$ about midnight and under quiet geomagnetic conditions, where the electron density at $85 \mathrm{~km}$ would normally be less than $500 \mathrm{el} / \mathrm{cc}$, it was found that received signal perturbations were significant, of the order of $1-4 \mathrm{~dB}$ and $5-40^{\circ}$ of phase. Perturbation amplitudes increase roughly as the square root of frequency. At short range perturbations are rather erratic, but more consistent at large ranges, readily interpretable in terms of the shifts in excitation factor, attenuation factor and $v / c$ ratios for Wait's modes. Under these conditions such shifts should be detectable by a well constituted experiment involving multiple paths and multiple frequencies in the north polar region in summer. It is anticipated that VLF propagation could be a valuable diagnostic for biteout/PMSE when electron density at $85 \mathrm{~km}$ is under $500 \mathrm{el} / \mathrm{cc}$, under which circumstances PMSE are not directly detectable by VHF/UHF radars.

Key words. Electromagnetism (wave propagation) - Ionosphere (polar ionosphere) - Radioscience (ionospheric propagation)

Correspondence to: D. Nunn

(dn@ecs.soton.ac.uk)

\section{Introduction}

Polar Mesospheric Summer Echoes (PMSE) have been observed at VHF and UHF frequencies (Cho and Rottger, 1997) as strong radar echoes from near the altitude of the Northern Hemisphere polar summer mesopause, located at $\sim 85 \mathrm{~km}$ altitude. It has been suggested that there is a possibility of observing the echoes at MF (Murphy and Vincent, 2000). All of these techniques involve the analysis of the return echo from radio waves launched in a near vertical direction by high power antenna arrays (Bremer et al., 1995). Observations have been mainly confined to the North Polar regions, though PMSE have been reported in Antarctica and also at mid-latitudes. PMSE events can last for more than an hour in some cases, often being seen for more than $30 \mathrm{~min}$ at a time (Palmer et al., 1996). The reflecting layers which lead to PMSE may have multiple structures and move dynamically on a time scale of minutes (Bremer et al., 1996). Theoretical investigations of the causes of PMSE are still ongoing, and are undoubtedly very complex. The phenomenon is clearly related to the extreme low temperatures prevailing at the summer mesopause, primarily in polar regions. PMSE are believed to result from scattering by enhanced small-scale spatial electron density fluctuations, arising from diminished electron density diffusivities due to the action of sub-visible aerosols, probably ice. From both observational and theoretical evidence, a minimum electron density exists at $\sim 85 \mathrm{~km}$ altitude of approximately $500 \mathrm{el} / \mathrm{cc}$ that is required to produce observable VHF/UHF radar echoes (Rapp et al., 2002). Below this density threshold the scattering of VHF/UHF waves becomes too weak to produce a detectable echo. It should be noted that interest in PMSE is not entirely confined to ionospheric plasma physicists. Since PMSE and related phenomena are critically dependent on the extremely low temperatures prevailing at the polar summer mesopause, the occurrence of PMSE may be a critical indicator of climate change and global warming (Bremer et al., 2003) 


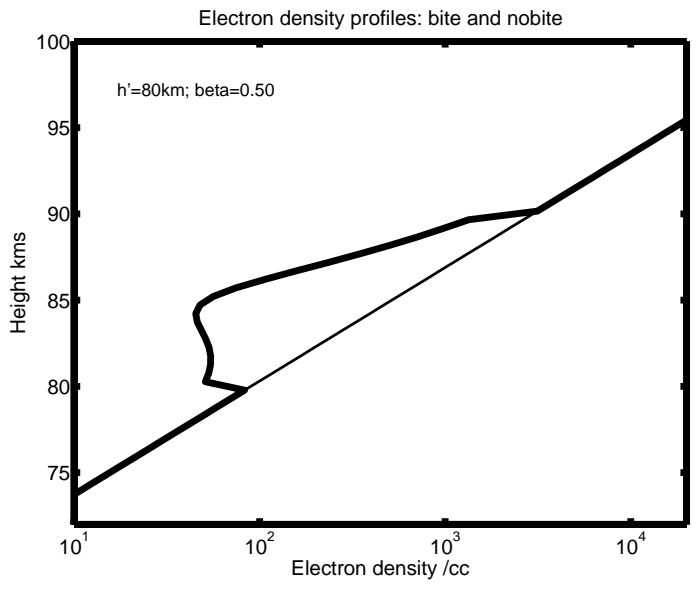

Fig. 1. Plot of ambient electron density profile and perturbed profile showing biteout.

Electron density "biteouts" have on occasion been observed by rocket instruments while radars have observed PMSE at adjacent heights (e.g. Ulwick et al., 1988), but PMSE do often occur without nearby electron density "biteouts" (Hoppe et al., 1994; Blix et al., 2003). Recent rocket campaigns at high latitudes have provided a significant number of D-region electron concentration profiles at the time of occurrence of PMSE (Goldberg et al., 2001). Typically "biteouts" in electron concentration occur near the altitudes of noctilucent clouds (Ulwick et al., 1988; Blix et al., 2003) and are thought to be due to the presence of aerosols scavenging lower ionospheric free electrons (Croskey et al., 2001). The "biteouts" are typically found at about $85 \mathrm{~km}$, have an altitude span of several kms, and have electron concentration levels that are reduced by around ten times.

Experimental observations of PMSE and electron density biteouts are confined to specific geographic locations and very limited information exists as to the spatial distribution of these phenomena at a specific time. Bremer et al. (1996) showed that significant similarities in PMSE observations could be detected over distances of $130 \mathrm{~km}$, although local features can be modified by processes such as gravity waves (Bremer et al., 1995). Radar cross section observations can change dramatically within a few minutes, which is also an indication of horizontal patchiness.

PMSE are sometimes observed in association with noctilucent clouds (NLC) (Thomas, 1991; Pfaff et al., 2001), although not always (Taylor et al., 1989). A mechanism to explain these observations has been suggested through subvisible electron-scavenging particles (which produce electron density biteouts) evolving to larger dimensions, sedimenting to lower altitude, and becoming visible optically as NLC (Hoppe et al., 1994). The two phenomena are similarly associated with the very cold summer polar mesosphere (Palmer et al., 1996). NLC occurs at $\sim 82 \mathrm{~km}$ in height, just below the altitude associated with PMSE, and consist of visible ice aerosols. Typically NLC are large-scale features, often being observed above significant fractions of the polar re- gions. Similar large-scale biteout structures could influence the propagation of long-path radio waves that reflect from the lower ionosphere near $85 \mathrm{~km}$ altitudes.

Here we use the well-developed NOSC long wave propagation model to investigate the impact of large-scale "biteouts" on the signal from very low frequency (VLF) transmitters over a range of frequencies $(20-80 \mathrm{kHz})$ and for transmitter-receiver path lengths varying from $500-6000 \mathrm{~km}$. Radio waves from manmade VLF transmitters propagate inside the waveguide formed by the lower ionosphere and the Earth's surface. Significant variations in the received amplitude and phase arise from changes in the lower ionosphere. These variations include those driven by changes in solar zenith angle (Thomson, 1993), solar flares (Deshpande and Mitra, 1972), lightning-induced electron precipitation (Helliwell et al., 1973), and red sprites (Hardman et al., 1998). Further discussion on the use of subionospheric VLF propagation as a remote sensing probe can be found in recent review articles (e.g. Barr et al., 2000; Rodger, 2003). We will show that significant phase and amplitude changes in VLF propagation may be observed when large-scale biteouts are present, and that it should be possible to detect such changes when ambient electron density concentration levels at $85 \mathrm{~km}$ are below $\sim 500 \mathrm{el} / \mathrm{cc}$, under which circumstances PMSE itself is not directly detectable by radar. The probing of electron density biteouts through subionospheric VLF propagation would provide a complementary observation technique and provide additional information about the scale and nature of electron biteouts and, by association, PMSE and NLC.

\section{The influence of biteouts on subionospheric VLF propagation}

VLF wave propagation codes, such as MODEFNDR and LWPC (Ferguson and Snyder, 1990), utilising Wait's classic modal theory (Wait and Spies, 1964; Wait, 1996), can be used to model the propagation of waves within the Earthionosphere waveguide and can therefore be used to investigate the impact of the electron concentration "biteouts". Although the vertical extent of the "biteouts" is typically less than the wavelength at VLF (about $10 \mathrm{~km}$ ), the oblique nature of the reflection at the upper boundary of the waveguide suggests that some changes in the VLF propagation characteristics of narrow-band signals from terrestrial VLF transmitters might be anticipated.

At mid-latitudes the background electron density profile at D-region altitudes is reasonably defined within VLF propagation codes by using the following equation for the electron density profile $N_{e}(z)$ (in electrons per cubic centimetre) (Wait and Spies, 1964),

$N_{e}(z)=7.855 \times 10^{-5} e^{\beta\left(z-h^{\prime}\right)} v(z)$,

where collision frequency $v$ (in collisions per second) is given by

$v(z)=1.816 \times 10^{11} e^{-0.15 z}$ 

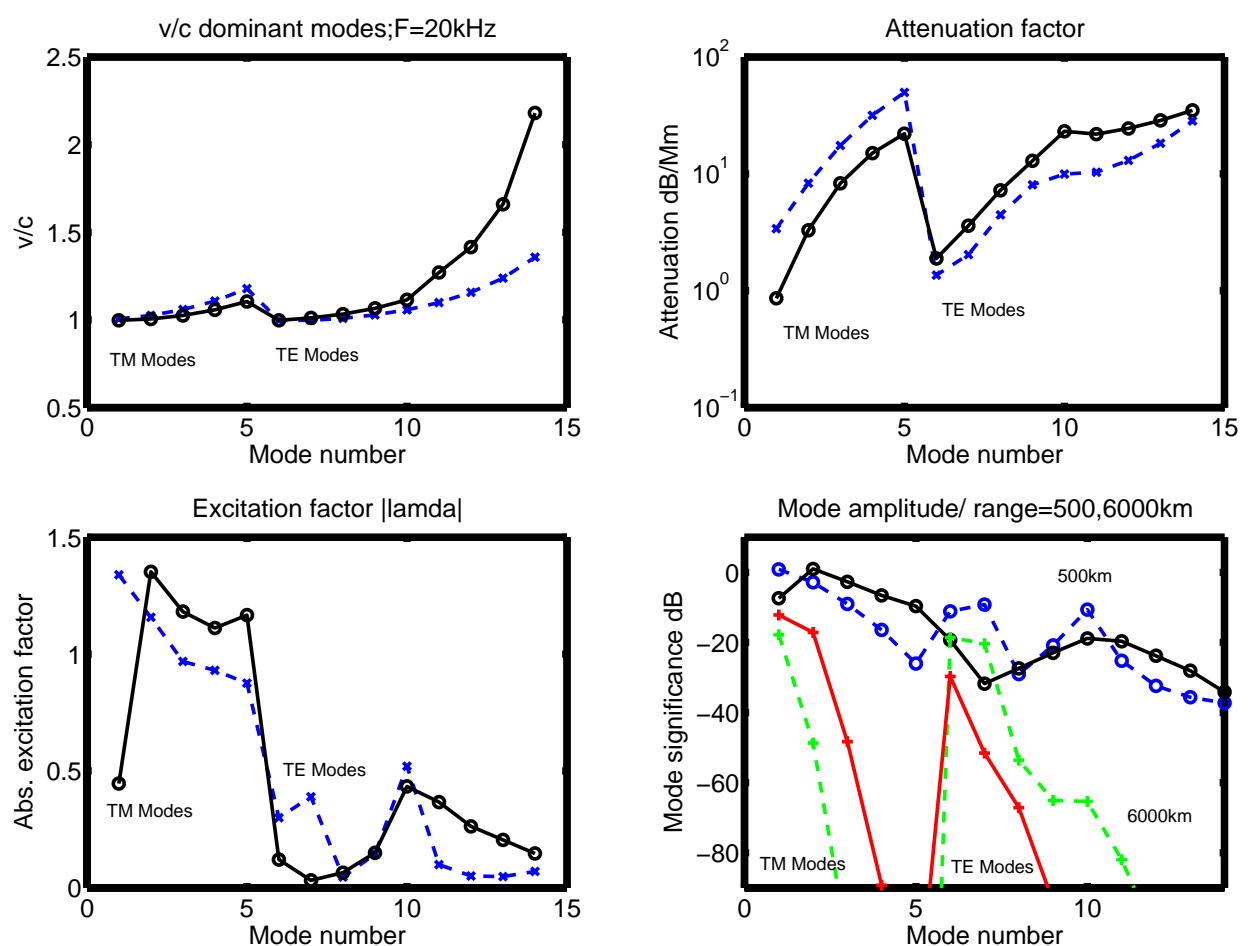

Fig. 2. Modal parameters at $f=20 \mathrm{kHz}$ for the profile given by $h^{\prime}=80 \mathrm{~km}, \beta=0.5 \mathrm{~km}^{-1}$. The solid lines are for the unperturbed profile, the dashed blue lines for the profile with biteout. The fourth panel shows modal amplitudes at the receiver at a range of $500 \mathrm{~km}$, the black line with circles being with no biteout, the blue line with circles with biteout. The corresponding figures at a range $6000 \mathrm{~km}$ are given by the dashed green line with crosses (biteout) and red line with crosses (no biteout).
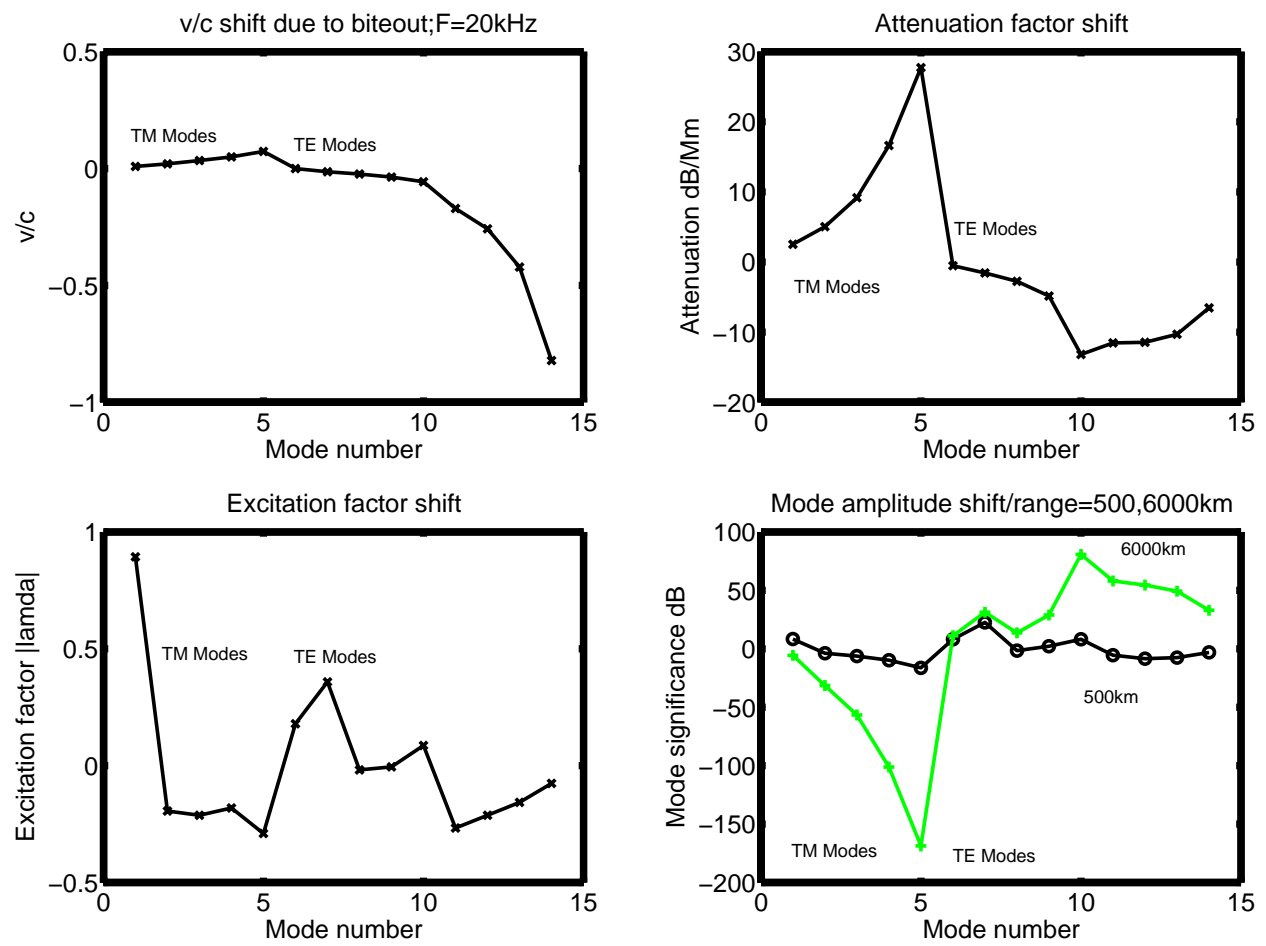

Fig. 3. Perturbations of modal parameters at $f=20 \mathrm{kHz}$ due to the biteout. The fourth panel shows change in modal composition, where the black line with circles is for a range of $500 \mathrm{~km}$ and the green line with crosses is for $6000 \mathrm{~km}$. Important features are the increased attenuation and increased phase velocity of dominant TM modes. 

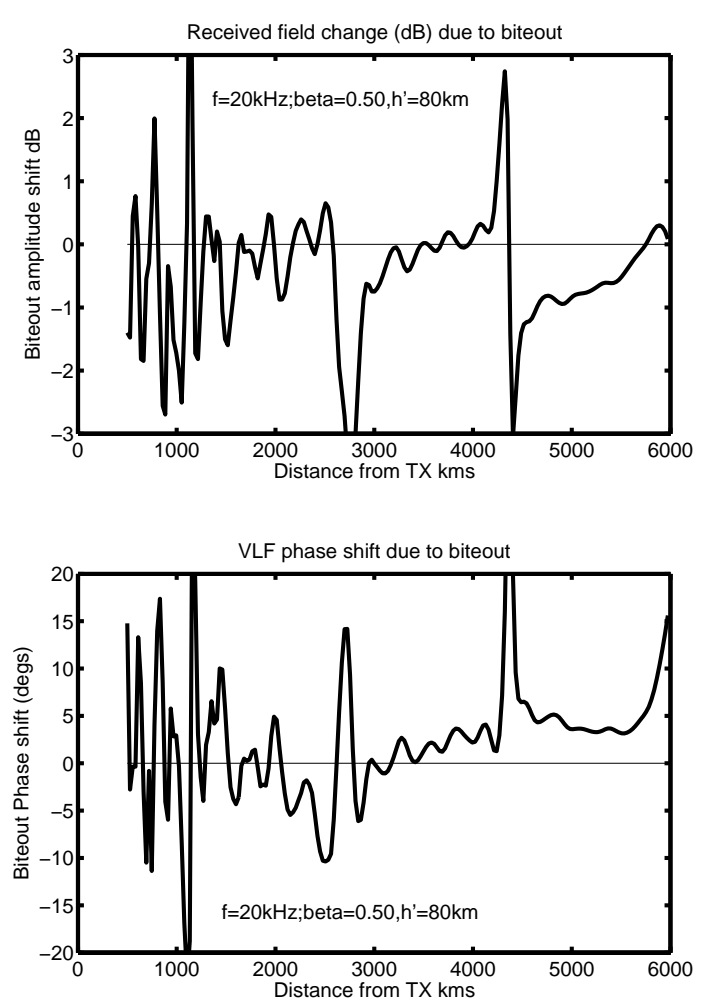

Fig. 4. Change in received amplitude and phase of subionospheric VLF propagation, due to biteout. The graph is for $f=20 \mathrm{kHz}$ and is plotted as a function of range. The perturbation is generally negative (typically $\sim-1 \mathrm{~dB}$ ) and positive phase (typically $\sim 4^{\circ}$ ) with spikes at modal interference minima. Propagation at short range is strongly multimodal, and received amplitude is rather unpredictable.

and $z$ is the altitude in kilometres. Here, $\beta$ represents the "sharpness" of the lower ionospheric boundary and $h^{\prime}$ represents the effective height of the ionosphere. Friedrich and Kirkwood (1999) show that at higher latitudes of $60-70^{\circ}$ this parameterisation can still hold during quiet geomagnetic conditions. Inspection of published rocket profiles shows that at the time and place of PMSE events under well illuminated conditions, the electron density profiles have values of $\sim 4000 \mathrm{el} / \mathrm{cc}$ at $85 \mathrm{~km}$ altitude, which is consistent with the typical value reported by Rapp et al. (2002). Typical "night-time" values for $\beta$ and $h^{\prime}$ at high latitudes during the summer months are likely to be $0.30 \mathrm{~km}^{-1}$ and $76 \mathrm{~km}$, respectively, which give $500 \mathrm{el} / \mathrm{cc}$ at $85 \mathrm{~km}$ altitude (Thomson, 1993; McRae and Thomson, 2000; Friedrich et al., 2002). This coincides with the minimum $85 \mathrm{~km}$ background electron concentration for PMSE VHF/UHF radar observations. However, as shown below, VLF propagation characteristics should be even more sensitive to "biteouts" during periods of lower electron density background levels, although these would be unlikely to occur for much of the time during wellilluminated polar summer conditions.
2.1 Details of the computation of VLF propagation perturbations

Our code calls as a subroutine a computer program developed by NOSC (Naval Ocean Systems Center, San Diego, USA) which returns all the parameters of the subionospheric VLF modes as described by Wait (1996). This program receives as inputs the frequency, ionospheric and geomagnetic parameters. Then, assuming horizontal homogeneity, the program calculates the appropriate full wave reflection coefficients for the waveguide boundaries and searches for those modal angles which give a phase change of $2 \pi$ across the guide. The computations take into account the curvature of the Earth, not by means of a spherical coordinate system, but by adding a radially dependent corrective term to the refractive index. A version of the program called MODESRCH is described and listed (in FORTRAN) by Morfitt and Shellman (1976). The program used for the mode parameter calculations reported here is a slightly modified version of the NOSC program MODEFNDR which is very similar to MODESRCH. Further discussion of the very complex mathematical details of the NOSC VLF propagation program and comparisons with experimental data can be found in Bickel et al. (1970) and Pappert and Hitney (1988).

The output of MODEFNDR then comprises the excitation factors, height gain functions, attenuation factors and horizontal wave numbers for allowable VLF modes. The main code uses modal theory to compute the amplitude and phase of the received VLF signal at zero altitude as a function of range from the transmitter. The field component computed is the vertical electric field $E_{z}$. In order to match the configuration of high power USN VLF transmitters, such as NAA $\left(44^{\circ} 38^{\prime} \mathrm{N}, 067^{\circ} 17^{\prime} \mathrm{W}, \sim 1 \mathrm{MW}\right)$, the transmitter is also assumed to be at zero altitude and comprises a vertical electric dipole. It should be pointed out that a transmitter built for research purposes, such as the Siple VLF station in Antarctica (Helliwell, 1988), could well adopt the alternative configuration of a horizontal electric dipole overlaying a low conductivity medium, such as ice or rock. In this case the propagation calculations would need to be redone. The selected frequencies are 20,40,60, and $80 \mathrm{kHz}$. The first of these corresponds closely to the frequencies used by USN VLF transmitters. The higher frequencies are intended to explore the frequency dependence of the biteout effect and also to inform experimental choices where various transmitters are available for use or may be specially constructed for research purposes.

The code uses all the modes returned by MODEFNDR, both TE and TM, in the modesum operation. The total number of modes used varies from 21 to about 60, depending on the transmitter frequency.

The path length between the transmitter and receiver is taken to vary from $500 \mathrm{~km}$ to $6000 \mathrm{~km}$ and to be over sea. Wait's modal theory will hold throughout our range of path lengths. The long path we have chosen might correspond to a transpolar path at about $60^{\circ}$ latitude. For most of the calculations we have used an undisturbed ionospheric profile with 

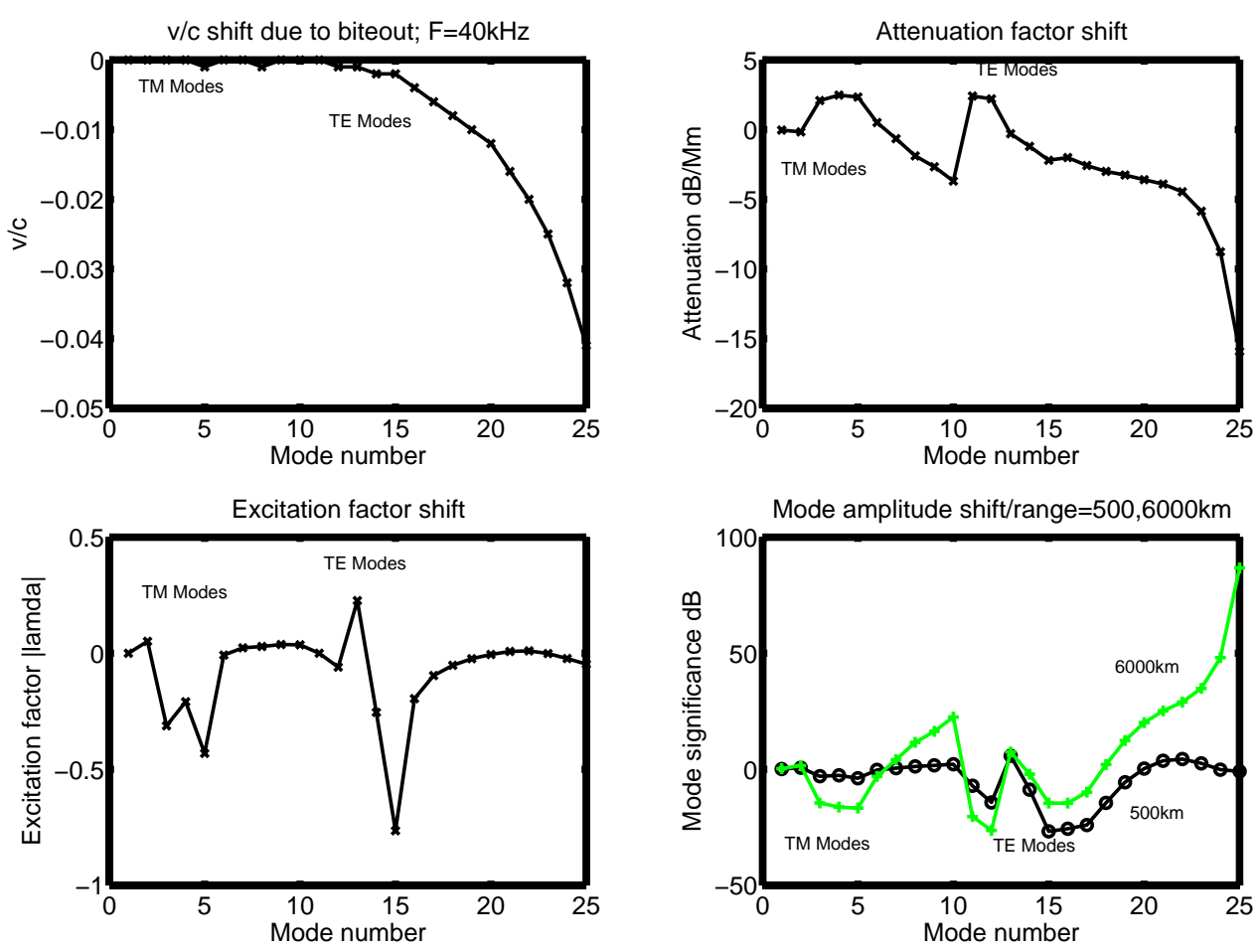

Fig. 5. Shifts in modal parameters at $f=40 \mathrm{kHz}$. Dominant modes are TM2-TM4. TE15 is of significance at short range and TE12-13 at longer ranges. Important features are increased attenuation and lower excitation for dominant modes TM3-TM5 and TE12.

$\beta=0.50$ and $h^{\prime}=80 \mathrm{~km}$, which gives an ambient electron density at $85 \mathrm{~km}$ of $500 \mathrm{el} / \mathrm{cc}$ and corresponds to a "night-time" low illumination situation. This electron density lies at the lower limit of PMSE detection in radar data, and is at the upper limit of biteout detection from VLF, as will be shown below. The background ionosphere is assumed to be homogeneous along the entire GC path, which will not be true for long paths. The code LWPC has the capability of dealing with long inhomogeneous paths and can calculate continuously the inter modal conversion that takes place along the GC path due to the inhomogeneity. However, LWPC is not an easy tool to use for scientific research. MODEFNDR requires a number of parameters, which are taken to be those appropriate to $68^{\circ}$ geographic latitude, namely ambient magnetic field strength $\left(B=5.3 \times 10^{-5} \mathrm{~W} / \mathrm{m}^{2}\right)$, ambient magnetic field codip angle $\left(166^{\circ}\right)$, and ground conductivity and dielectric constant (81) of sea water. The direction of the GC path is taken to be magnetic west to east.

Based upon the rocket observations of Ulwick and coworkers, the "biteout" is modelled as a truncated Gaussian depletion profile, with a maximum of $90 \%$ located at $85 \mathrm{~km}$, and extending from $80-90 \mathrm{~km}$. Both the unperturbed electron density profile and the profile with biteout are shown in Fig. 1. It is assumed that the biteout exists throughout a corridor of some $300 \mathrm{~km}$ wide along the entire GC path. This may be a somewhat unrealistic assumption, particularly for long paths $\sim 6000 \mathrm{~km}$. However, in view of the fact that the spatial distribution of the biteout is poorly known, there is clearly no sensible alternative strategy. Futhermore, no simulation code currently exists which would enable one to compute VLF propagation perturbations due to a biteout with arbitrary horizontal structure. The reader should therefore interpret the computed results for long ranges with some care and bear in mind that actual biteout distribution within the GC corridor could well be patchy or of limited extent. In that sense the VLF perturbations calculated here must be regarded as upper limits. There is observational evidence that NLCs, when they occur, have a wide spatial distribution across the polar regions. If particles have evolved enough to produce NLC then they will have gone (or be going) through the electron scavenging phase (Hoppe et al., 1994). This would suggest that extensive NLC clouds would be associated with equally extensive occurrences of PMSE and biteout, though not necessarily at the same time. However, some observations show (Hoppe et al., 1994) that the correlation between NLCs and PMSE is in fact not that high.

Computation of VLF perturbations due to a "spatially inhomogeneous biteout" would be difficult indeed. Certainly the techniques used by Nunn (1997), Rodger and Nunn (1999) and Nunn and Strangeways (2000) to compute "Trimpis" due to lightning-induced electron precipitation would be inappropriate, since the modification to the electron density profile due to the biteout is strong, leading to non-Born, nonlinear scattering. In addition, the biteout is located at an altitude where MODEFNDR's height gain functions are inaccurate, and the large spatial extent of the biteout would make scattering computations very expensive. 

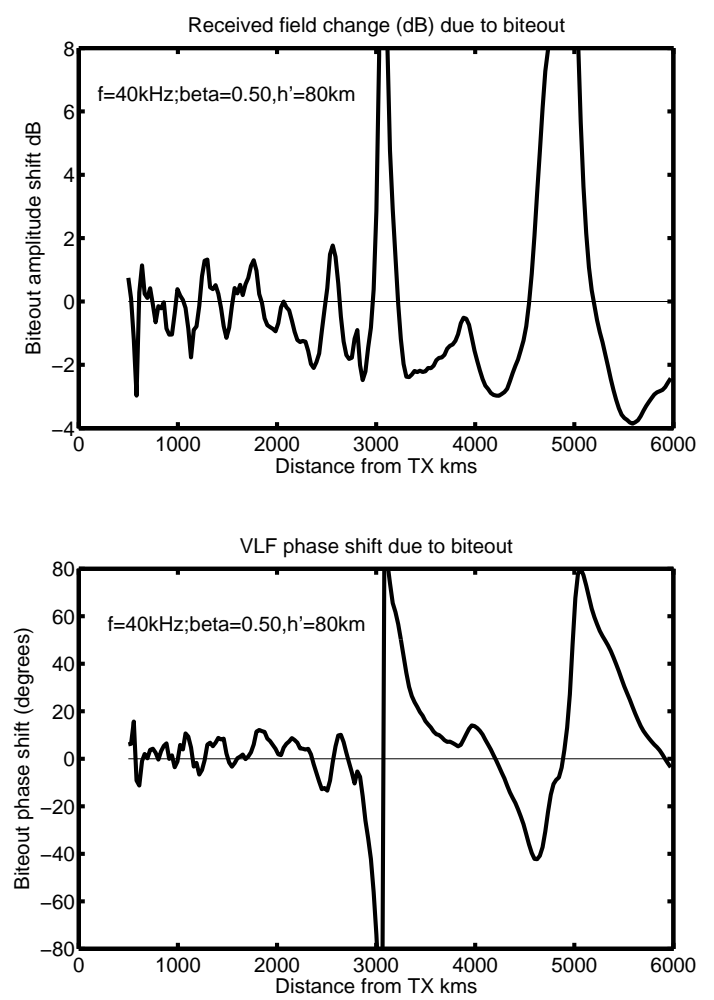

Fig. 6. Change in subionospheric received VLF amplitude and phase due to biteout, at $f=40 \mathrm{kHz}$. Amplitude shifts are not inconsiderable at about $-2 \mathrm{~dB}$, with positive spikes at modal minima. Phase shifts are variable and up to $10^{\circ}$ inside the first modal minimum at $3000 \mathrm{~km}$. At long range large shifts up to $80^{\circ}$ are indicated with a preference for positive sign.

An alternative approach to the modelling of Trimpis was adopted in Poulsen et al. $(1990,1993)$. They based their computations on an expression due to Wait (1964) which assumes linear Born scattering and a large, slowly varying ionospheric perturbation, allowing one to neglect intermodal coupling in the scattering process. Given more data on the spatial distribution of a biteout, this approach could indeed be used to model the VLF perturbations due to a patchy biteout of finite extent.

The rigorous solution to the problem would involve 3-D finite element modelling at huge computational expense. Thus far only 2-D finite element codes have been developed for modelling subionospheric VLF propagation under an inhomogeneous ionosphere (Baba and Hayakawa, 1996).

Perhaps an equally attractive approach to the problem of subionospheric VLF propagation under an inhomogeneous ionosphere is to use a time domain FDTD integration (Berenger, 1994, 2002). While conceptually simpler than Finite Element methods, nonetheless the computational load is high, and thus far only 2-D models have been developed.

The MODEFNDR code we employ here computes received $E_{z}$ phase (relative to free space propagation) and amplitude as a function of range for the profile, with and without biteout. We present the result as the change in propa- gation amplitude and phase resulting from the biteout. These shifts of course apply equally well to the horizontal magnetic field components perpendicular to the direction of propagation, namely $B_{x}$ and $B_{y}$. It is these changes that are to be the VLF diagnostic for electron density biteouts, and to the extent that biteout occurrence correlates with PMSE, they become diagnostics for PMSE.

\section{Computed results for VLF propagation}

\subsection{Propagation at $20 \mathrm{kHz}$}

Prior to examining the VLF amplitude and phase shifts due to biteouts, it is a useful exercise to examine the modal mix at each frequency, the parameters appertaining to each mode, and how they are shifted by the biteout.

Figure 2 displays the modal parameters at $20 \mathrm{kHz}$. The modes returned by MODEFNDR have been re-ordered with TM modes first followed by the TE modes. All modes whose contribution is entirely negligible at ranges between 500 and $6000 \mathrm{~km}$ have been ignored. The top left panel shows $v / c$, the wave phase velocity $v=\omega / k_{\|}$relative to $c$. This is greater than unity since $\cos \theta \sim c / v$, where $\theta$ is the propagation angle relative to horizontal at the reference height. The dashed blue curve (with $\mathrm{x}$ ) represents the corresponding result with biteout. Of the nonnegligible propagation modes found by the code, 5 are TM modes and 9 are TE modes. The higher order modes clearly have increasing propagation angles. The top right panel shows modal attenuation factor in $\mathrm{dB} / \mathrm{Mm}$. Attenuation increases to large values for higher order modes. The leading TE modes have low attenuation and may be important at long range. The bottom left panel shows $|\lambda|$, the absolute value of Wait's excitation factors. As is well known, in the case of vertical electric dipole excitation, TM modes are strongly excited and TE modes weakly excited. The fourth panel estimates the relative modal mix at the minimum range of $500 \mathrm{~km}$ (black, solid, $\mathrm{x}$; biteout blue, dashed, o) and the maximum range of $6000 \mathrm{~km}$ (red, solid, $\mathrm{x}$; biteout green, dashed, $x$ ). Clearly at short range we have a very broad modal mix, with TM1-TM5 modes being of significance as well as TE10. At long range TM1 and TM2 and TE6 alone are significant.

Figure 3 plots the corresponding shifts in the modal parameters due to biteout at $20 \mathrm{kHz}$. These are important since it is these shifts ultimately that give rise to the propagation perturbations. The parallel phase velocity is increased for TM modes but decreased for TE modes. Attenuation increases for TM modes but decreases for TE modes. There is a large increase in excitation for TM1, other TM modes being less excited. Low-order TE modes are more strongly excited, in particular making TE7 more significant at long range. The solution of the modal equation is highly complex and it is difficult to formulate simple explanations for these results. The fourth panel shows the shift in modal amplitude at ranges of $500 \mathrm{~km}$ (black) and $6000 \mathrm{~km}$ (green). The effect 

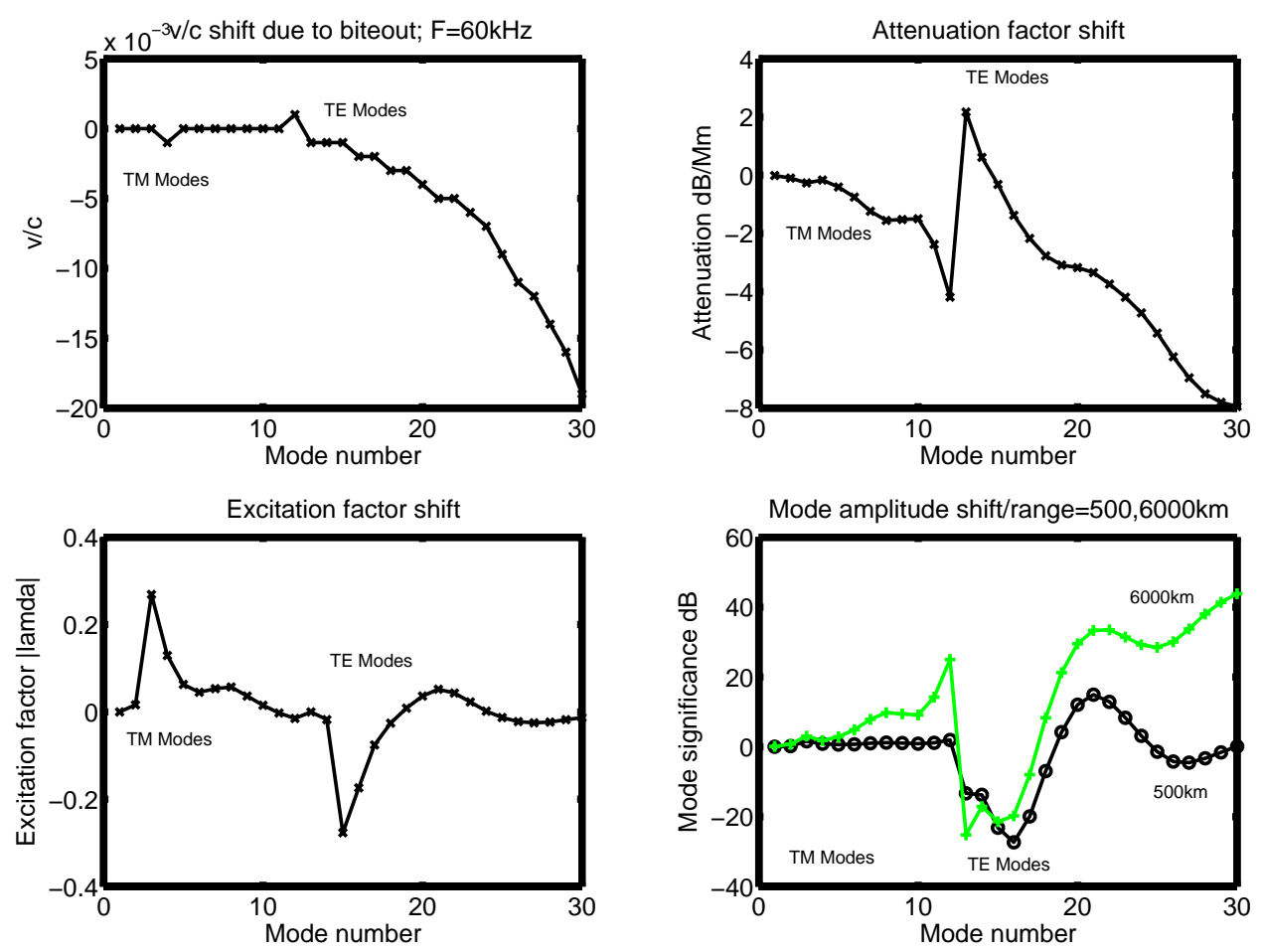

Fig. 7. Shift in modal parameters due to biteout at $f=60 \mathrm{kHz}$. Key features are the decreased attenuation and increased excitation of TM modes and decreased phase velocity of TE modes.

of biteout is to raise the significance of TE6 and TE7, but reduce that of TM2-TM5.

Figure 4 plots the shift in VLF received amplitude (in $\mathrm{dB}$ ) and phase at $20 \mathrm{kHz}$ as a function of range. At ranges less than $2800 \mathrm{~km}$, many modes are significant in the received signal and the resulting shift, though significant and in the region of $1-2 \mathrm{~dB}$, is highly variable and unpredictable. The very large perturbations $\sim \pm 3 \mathrm{~dB}$ at $2800 \mathrm{~km}$ and $4400 \mathrm{~km}$ correspond to the location of modal interference minima. Beyond $4000 \mathrm{~km}$ the general effect of biteout is a reduction of received amplitude by about $1 \mathrm{~dB}$. Regarding received phase a similar pattern is observed, chaotic at short range, with sharp maxima at modal minima. At large ranges a coherent pattern emerges with phase advances in the region of $4^{\circ}$. The behaviour at long range, where a few TM modes dominate, is consistent with our modal investigation. The negative amplitude change and positive phase shift is consistent with the dominant TM modes undergoing increased attenuation and phase velocity and decreased excitation factor. The increased excitation of TM1 is not enough to counteract this pattern.

It is interesting to note that VLF propagation perturbations at long ranges $(\sim 6000 \mathrm{~km})$, even assuming the biteout covers the whole GC corridor, are no larger than those calculated for short range. This suggests that experiments could be usefully set up using short paths only. In addition, this indicates that biteouts covering a significant fraction of the $\sim 6 \mathrm{Mm}$ path will lead to similar changes as that determined, assuming the entire path has biteout conditions.

\subsection{Propagation at $40 \mathrm{kHz}$}

Figure 5 show the shifts in modal parameters due to biteout at $40 \mathrm{kHz}$. These are rather different due to different degrees of penetration of the modes to $85 \mathrm{~km}$ and the different correlations between the biteout and height gain function profiles. The shifts in parallel phase velocities are much smaller and negligible for the TM modes but substantially negative for TE modes. The dominant TM and TE modes have increased attenuation, the others having reduced attenuation. The dominant TM modes have reduced excitation.

Figure 6 plots the received VLF amplitude and phase shifts at $40 \mathrm{kHz}$. Inside the first modal interference minimum at $3000 \mathrm{~km}$ the shifts are irregular in the region of $10^{\circ}$ of phase and $1 \mathrm{~dB}$. Beyond this range amplitude shift is in the region of $-2 \mathrm{~dB}$, but becomes large and positive $(\sim 8 \mathrm{~dB})$ at the next minimum at $5000 \mathrm{~km}$. Negative amplitude shifts are due to the increased attenuation and decreased excitation of the dominant TM modes. Phase shifts at ranges larger than $3000 \mathrm{~km}$ are substantial $\left(\sim 40^{\circ}\right)$ but of unpredictable sign and are harder to interpret.

\subsection{Propagation at $60 \mathrm{kHz}$}

Figure 7 shows the modal parameter shifts at $60 \mathrm{kHz}$ and indicates small negative changes in parallel phase velocity for TE modes, decreasing attenuation for the TM modes and TE modes, with the exception of the leading TE modes TE13 and TE14. Dominant TM modes TM3 and TM4 have a considerable increase in excitation factor. Figure 8 shows the 

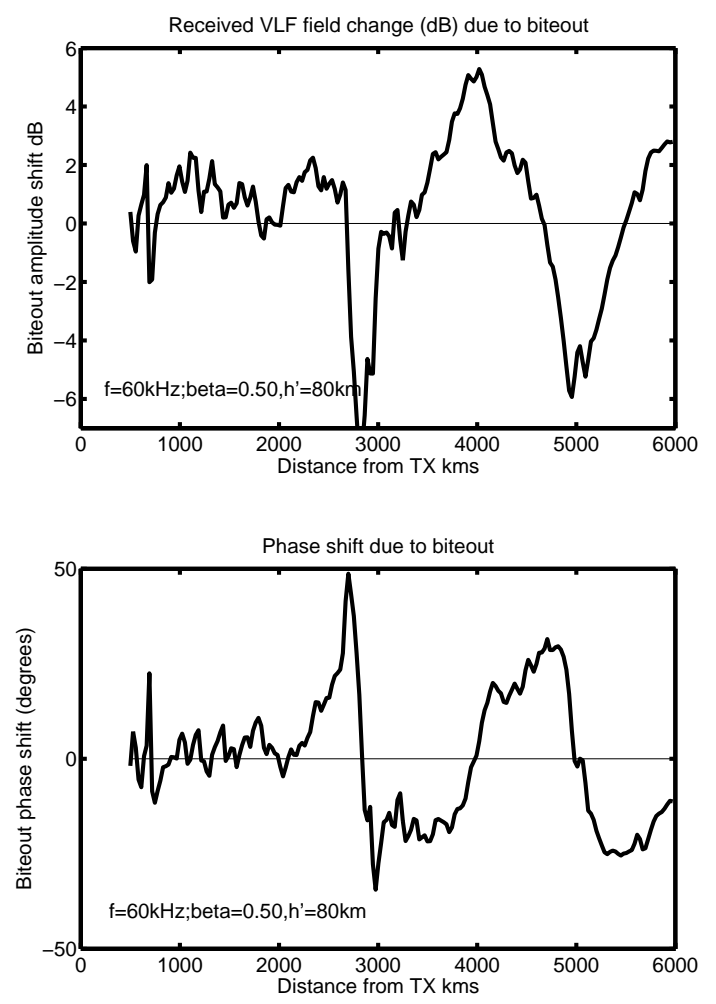

Fig. 8. Change in subionospheric received VLF amplitude and phase due to biteout, at $f=60 \mathrm{kHz}$. The general trend is for a positive shift, up to a substantial maximum of $5 \mathrm{~dB}$, but with large negative spikes at modal minima. Inside $3000 \mathrm{~km}$ the shift is between 0 and $+2 \mathrm{~dB}$. Phase shifts at large range seem to be $\pm 20^{\circ}$, with smaller values up to about $8^{\circ}$ inside $2000 \mathrm{~km}$.

VLF amplitude and phase shifts at $60 \mathrm{kHz}$. The former are generally positive and $\sim 2 \mathrm{~dB}$ inside the first modal minimum at $3000 \mathrm{~km}$, which is due to decreased attenuation and increased excitation factors of the dominant TM modes. Phase shifts inside the first modal minimum are small $\sim 7^{\circ}$ and of indeterminate sign. Beyond $3000 \mathrm{~km}$ amplitude and phase shifts are quite large $\left(\sim 20^{\circ}, 4 \mathrm{~dB}\right)$ but can be of either sign depending on range.

\subsection{Propagation at $80 \mathrm{kHz}$}

Figure 9 show the modal parameter shifts at $80 \mathrm{kHz}$. A fairly consistent pattern is seen, namely a decrease in parallel phase velocity in the case of TE modes, decreased attenuation for all modes and small increases in excitation factor. These changes are reflected in Fig. 10, showing propagation perturbations at $80 \mathrm{kHz}$. The overall amplitude shift is positive and quite substantial in the range $1-4 \mathrm{~dB}$. A strong negative peak from -2 to $-6 \mathrm{~dB}$ stretching across the range 3100 $3400 \mathrm{~km}$ is seen in the region of the modal interference minimum at $3200 \mathrm{~km}$. There is a good deal of variability related to the multimodal character of the propagation. The phase shift is consistently negative at a substantial value $\sim-20^{\circ}$, except for a large positive peak at $2900 \mathrm{~km}$. This is due in part to the decrease in parallel phase velocity for all modes.

\section{Profile and frequency dependence of VLF propaga- tion disturbances}

It is a matter of some interest and importance as to how the overall magnitude of VLF propagation amplitude and phase shift depend on unperturbed electron density profile and on frequency. During the course of this research numerous profiles were investigated. It became clear that the perturbation size could be viewed as depending on the unperturbed ambient electron density at the biteout level of $85 \mathrm{~km}$. We have selected four diverse profiles and plotted the mean absolute value of perturbation (both amplitude and phase) at long range, as a function of ambient density at $85 \mathrm{~km}$. Figure 11 shows these results for all four frequencies. It is apparent that once the ambient electron number density at $85 \mathrm{~km}$ exceeds about $500 \mathrm{el} / \mathrm{cc}$, the size of the perturbation of VLF propagation collapses to negligible levels, due, of course, to shielding and the non penetration of the modal height gain functions to the biteout altitude of $85 \mathrm{~km}$. Conversely, for profiles with generally lower electron densities, associated with night/dusk/low solar elevation, VLF propagation changes become very large, for example, $8 \mathrm{~dB}$ and $80^{\circ}$ in one case.

Another matter of considerable interest is the frequency dependence of the size of the propagation disturbances. As far as phase shift is concerned, this seems to increase somewhat with frequency (roughly as $\sqrt{ } f$ ) for low density profiles. The same may be said for the magnitude perturbation, except for $20 \mathrm{kHz}$, which has an anomalously large value. With denser profiles a clear frequency dependence is hard to discern, except that $20 \mathrm{kHz}$ is here anomalously low, for both amplitude and phase perturbations. The dependence of modal parameters on profile is immensely complex, and these dependencies are presumably due to the extent to which each mode penetrates to the biteout altitude and the correlation of the biteout profile with the height gain functions.

Given the apparent upper limit of $500 \mathrm{el} / \mathrm{cc}$ for the production of significant signatures of biteouts in VLF signals we would expect preferred periods when they could be observed. We can estimate the electron number density levels at $85 \mathrm{~km}$ by using the solar zenith angle control of $\beta$ and $h^{\prime}$ and fitting of the ionospheric profile through experimentally determined (empirical) relationships (Thomson, 1993; McRae and Thomson, 2000). Figure 12 shows the expected diurnal variation of the electron density at the summer solstice on 21 June for latitudes of 60,65 , and $70^{\circ}$. The electron density is shown by the roughly sinusoidally varying line in this figure. That section of the line marked by circles corresponds to the solar zenith angle range $\left(<80^{\circ}\right)$ over which the empirical expressions were developed. Beyond this area the electron density values can only be considered approximate. The horizontal line indicates the cutoff level of $500 \mathrm{el} / \mathrm{cc}$. Calculations for 21 July, one month after the summer solstice, gave a similar result. It can be seen that the VLF technique is potentially able to operate successfully for about $10 \mathrm{~h}$ per day, centred about midnight, during the arctic summer PMSE season. This estimate is confirmed by the quiet-time ionosphere models for auroral latitudes developed by Friedrich 

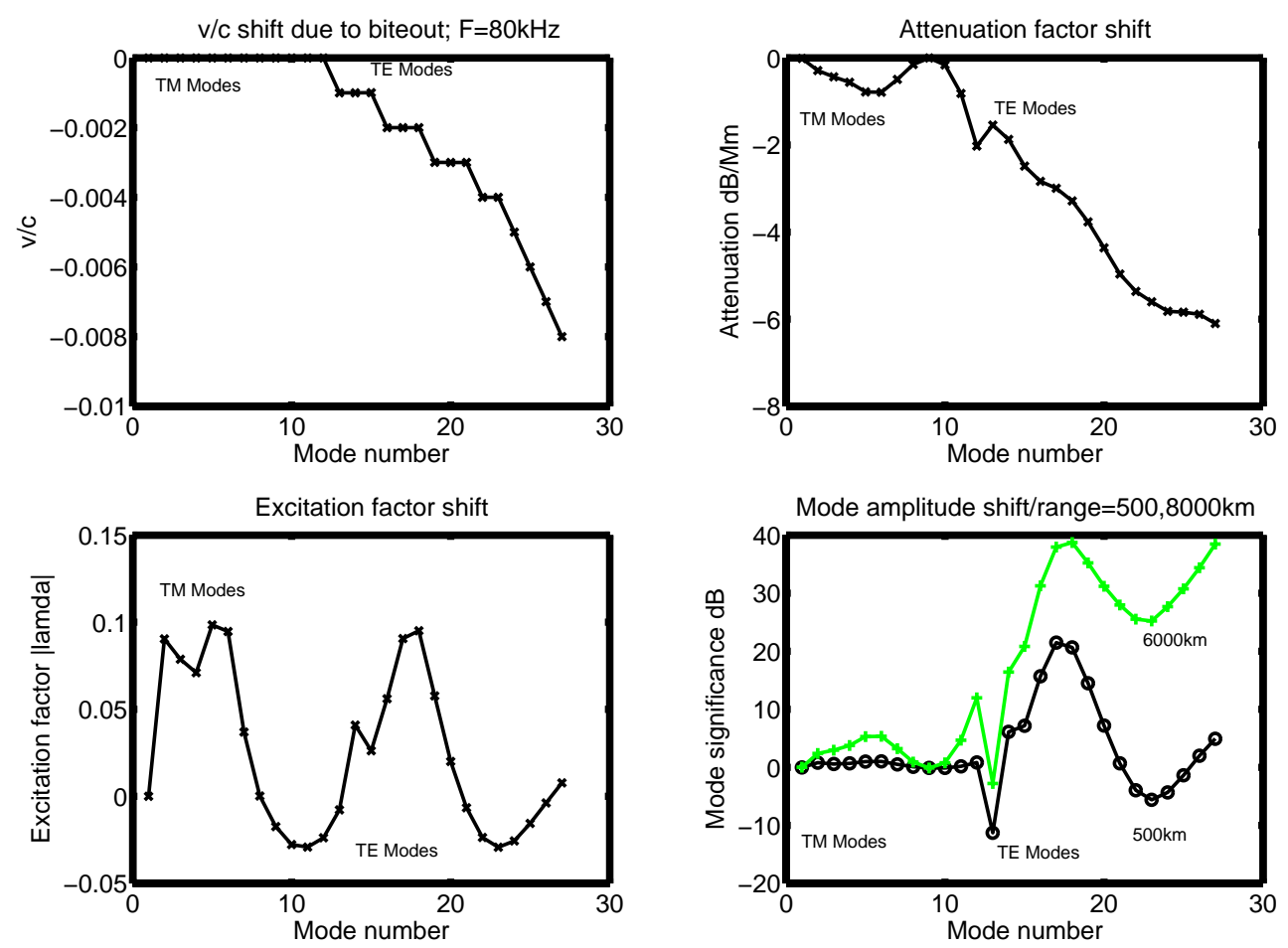

Fig. 9. Shift in modal parameters due to biteout at $f=80 \mathrm{kHz}$. Key features are the decreased attenuation and increased excitation of TM modes and decreased phase velocity of TE modes.

et al. (2001) (Personal communication, R. Steiner, 2003). This empirical model suggests an observation window for our VLF technique of about $6 \mathrm{~h}$ at $60^{\circ}$ latitude and probably less at higher latitudes. Significant increases in background electron density at $85 \mathrm{~km}$ would be expected during any geomagnetic activity periods, which would result in the exclusion of the VLF wave from the biteout altitudes. Thus, quiet geomagnetic conditions would be a necessary condition to detect the VLF signature of large-scale biteouts.

\section{Conclusions}

We have determined that realistic "biteouts" of the electron density profiles can cause observable changes in subionospheric VLF propagation characteristics. These results were calculated under the assumption that the biteout covers a $300 \mathrm{~km}$ corridor along the whole GC path. For ambient profiles, with densities $\sim 500 \mathrm{el} / \mathrm{cc}$ at $85 \mathrm{~km}$, which is on the low side and associated more with the $10 \mathrm{~h}$ period about midnight, perturbations were of the order of $1-2 \mathrm{~dB}$ and $10-20^{\circ}$. The dependence of perturbation on range was quite erratic at relatively short ranges $<2500 \mathrm{~km}$, due to the multimodal nature of the propagation for these distances. At longer ranges a more settled pattern emerged, with negative amplitude and positive phase shift predominating at $20 \mathrm{kHz}$ and the opposite at $80 \mathrm{kHz}$. The patterns at 40 and $60 \mathrm{kHz}$ were less straightforward. Perturbations are sharply dependent on ambient density at $85 \mathrm{~km}$, quickly collapsing when density exceeds about $500 \mathrm{el} / \mathrm{cc}$, but becoming large for lower densities.
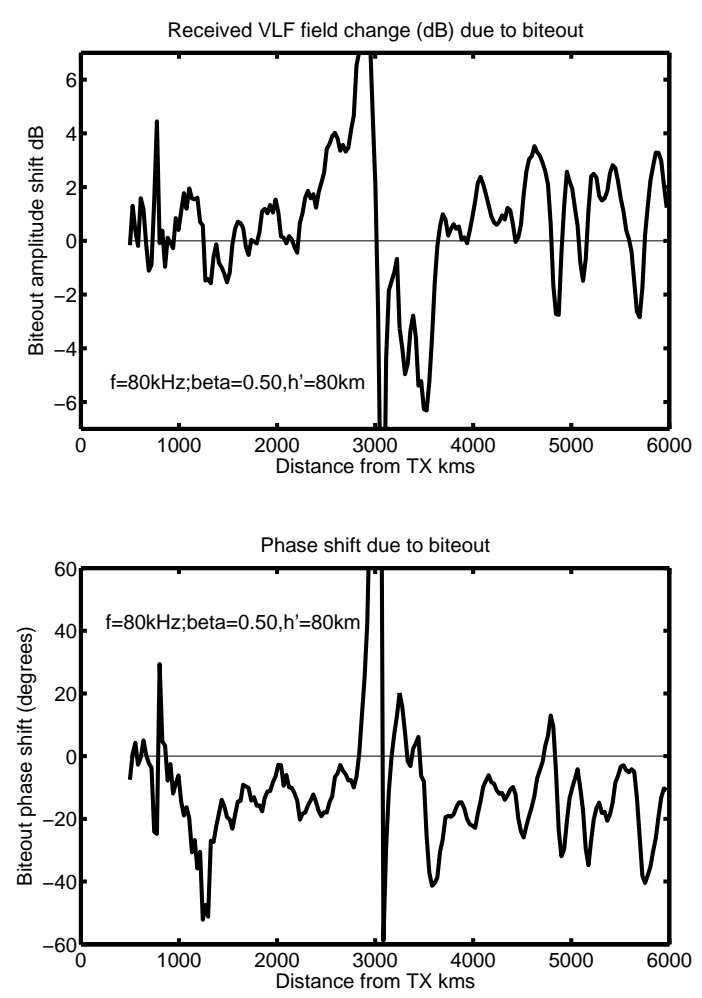

Fig. 10. Change in subionospheric received VLF amplitude and phase due to biteout, at $f=80 \mathrm{kHz}$. At this frequency the shift shows a complex pattern, and is mainly positive at a typical level of $+2 \mathrm{~dB}$. A fairly consistent pattern of negative phase shifts $\sim-20^{\circ}$ will be noted. 

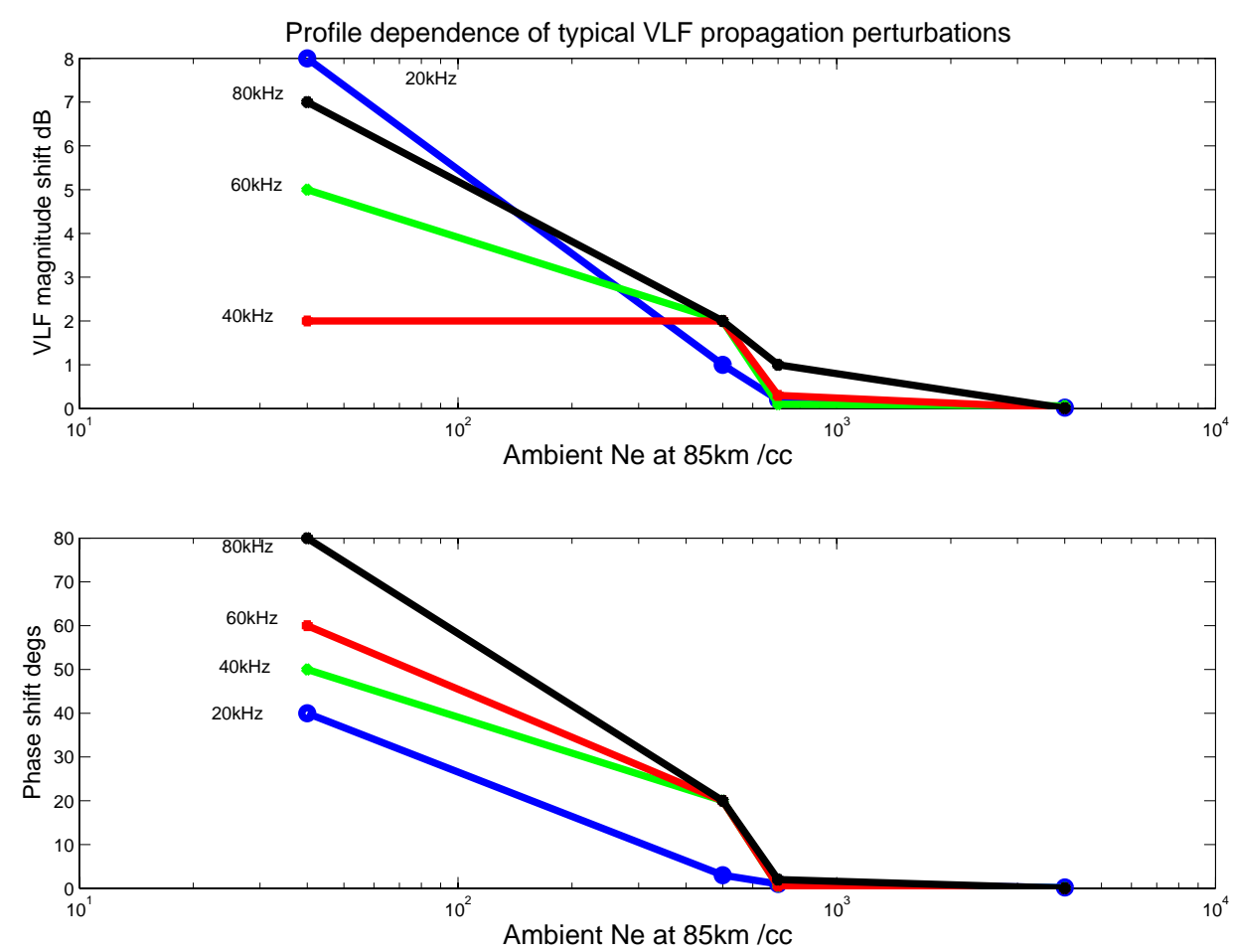

Fig. 11. Variation of the VLF amplitude and phase perturbations with frequency and ambient electron density at $85 \mathrm{~km}$. We have utilised median values of the magnitudes of amplitude and phase perturbations at long range. Note the rapid increase as density decreases below $500 \mathrm{el} / \mathrm{cc}$. Overall perturbation magnitude increases with frequency.

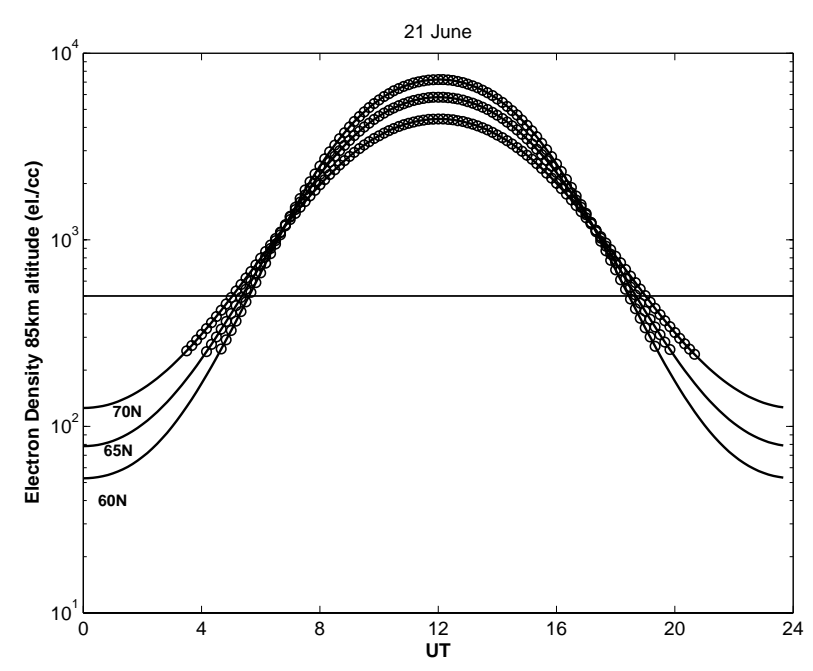

Fig. 12. Estimated electron density at $85 \mathrm{~km}$ at the summer solstice (21 June) as a function of universal time at $60,65,70 \mathrm{~N}$ and at zero longitude. Below the horizontal line at $500 \mathrm{el} / \mathrm{cc}$ we expect feasible VLF detection of electron density biteouts.
Taking a global view, the VLF perturbations increased somewhat with frequency.

Thus, as a means of detecting Biteouts/PMSE, VLF propagation would appear to be effective when ambient densities at $85 \mathrm{~km}$ are less than $500 \mathrm{el} / \mathrm{cc}$. This is precisely the domain where PMSEs are not reported in radar data, and thus, VLF may be the basis of a valuable complimentary measurement technique.

This research suggests experimental programs in which trans-arctic VLF propagation paths are selected and VLF propagation in summer is closely monitored and compared with the incidence of observed PMSE and noctilucent clouds, or indeed direct rocket observations of biteout. As a diagnostic, VLF propagation shifts will be a measure of the integrated effect of an electron density biteout along a GC corridor, connecting a given transmitter and receiver, in contrast to rocket/PMSE measurements which are essentially point measurements. A key factor here will be the stability of the VLF propagation. One will be observing shifts in VLF amplitude and phase as biteouts develop along or move through the GC corridor. The detectability of these shifts will in part depend upon the typical time signature of the VLF propagation shifts and how they compare with the time signatures of all the other causes of VLF propagation variability. Certainly use of multiple frequencies and multiple paths can only improve the probability of biteout detection and/or reduce the false alarm rate. Observations can reasonably be confined to periods when the ambient profile is known to be "weak", 
i.e. under quiet magnetic conditions and around midnight. In this regard it would also appear to be beneficial to site the receiver close to a multimodal interference minimum.

Regarding future work such experiments would require further modelling for specified paths, in which the dependence of VLF perturbations on biteout altitude and depth was investigated. The problem of modelling biteouts with a patchy horizontal distribution remains difficult. If one can assume weak Born scattering and negligible intermodal coupling, as well as a homogeneous background ionosphere, the use of the formalism in Wait (1964) would certainly provide a solution. A more rigorous treatment would require 3-D FDTD codes or 3-D finite element codes, through the future development of existing 2-D codes (Baba and Hayakawa, 1996). In addition, further knowledge on the characteristics of biteouts are required in order for more realistic calculations to be made. Some information may be gained by the joint deployment of radar and VLF observational systems in campaign environments.

Acknowledgements. The authors wish to thank NOSC, San Diego, for permission to use the MODEFNDR software.

Topical editor U.-P. Hoppe thanks a referee for his help in evaluating this paper.

\section{References}

Baba, K. and Hayakawa, M.: Computational results of the effect of localised ionospheric perturbations on subionospheric VLF propagation, J. Geophys. Res., 101, A5, 10 985-10 993, 1996.

Barr, R., Jones, D. L., and Rodger, C. J.: ELF and VLF Radio Waves, J. Atmos. Sol. Terr. Phys., 62, 17-18, 1689-1718, 2000.

Berenger, J. P.: A perfectly matched layer for the absorption of electromagnetic-waves, J. Comput. Phys., 114, 185-200, 1994.

Berenger, J. P.: FDTD computation of VLF-LF propagation in the Earth-ionosphere waveguide, Ann. Telecommun., 57, 10591090, 2002.

Bickel, J. E., Ferguson, J. A., and Stanley, G. V.: Experimental observation of magnetic field effects on VLF propagation at night, Radio Science, 5, 19, 1970.

Blix, T., Rapp, M., Lübken, F.-J.: Relations between small-scale electron number density fluctuations, radar backscatter, and charged aerosol particles, J. Geophys. Res., 108, D8, 8450, 2003.

Bremer, J., Singer, W., Keuer, D., Hoffman, P., Rottger, J., Cho, J. Y. N., and Schwartz, W. E.: Observations of Polar Mesospheric Summer Echoes at EISCAT during Summer 1991, Radio Science, 30, 4, 1219-1228, 1995.

Bremer, J., Hoffman, P., Singer, W., Meek, C. E., and Ruster, R.: Simultaneous PMSE Observations with ALOMAR-SOUSY and EISCAT-VHF Radar During the ECHO-94 Campaign, Geophysical Research Letters, 23, 10, 1075-1078, 1996.

Bremer J., Hoffmann, P., Latteck, R., and Singer, W.: Seasonal and long-term variations of PMSE from VHF radar observations at Andenes, Norway, J. Geophysical Research-Atmospheres, 108 (D8): art. no. 8438, Feb 8, 2003.

Cho, J. Y. N. and Rottger, P.: An Updated Review of Polar Mesosphere Summer Echoes: Observation, Theory, and their Relationship to Noctilucent Clouds and Subvisible Aerosols, J. Geophys. Res., 102, D2, 2001-2020, 1997.
Croskey, C. L., Mitchell, J. D., Friedrich, M., Torkar, K. M., Hoppe, U.-P., and Goldberg, R. A.: Electrical Structure of PMSE and NLC Regions during the DROPPS Program, Geophysical Res. Letters, 28, 8, 1427-1430, 2001.

Deshpande, S. D. and Mitra, A. P.: Ionospheric effects of solar flares IV, Electron density profiles deduced from measurements of SCNA's and VLF phase and amplitude, J. Atmos. Terr. Phys., 34, 255-266, 1972.

Ferguson, J. A. and Snyder, F. P.: Computer Programs for Assessment of Long Wavelength Radio Communications, Naval Oceans Systems Centre Technical Document 1773, 1990.

Friedrich, M. and Kirkwood, S.: The D-region background at high latitudes, Adv. Space Res., 25, 1, 15-23, 1999.

Friedrich, M., Torkar, K. M., Harrich, M., Pilgram, R., and Kirkwood, S.: On merging empirical models for the lower ionosphere of auroral and non-auroral latitudes, Adv. Space Res., 29, 6, $929-$ 935, 2002.

Goldberg, R. A., Pfaff, R. F., Holzworth, R. H., et al.: DROPPS: A study of the Polar Summer Mesosphere with Rocket, Radar and Lidar, Geophysical Res. Letters, 28, 8, 1407-1410, 2001.

Hardman, S., Rodger, C. J., Dowden, R. L., and Brundell, J. B.: Measurements of the VLF scatter pattern of the structured plasma of red sprites, IEEE Antennas Propag. Mag., 40, 29-38, 1998.

Helliwell, R. A., Katsufrakis, J. P., and Trimpi, M. L.: Whistlerinduced amplitude perturbation in VLF propagation, J. Geophys. Res., 78, 4679-4688, 1973.

Helliwell, R. A.: VLF wave stimulation experiments in the magnetosphere from Siple Station, Antarctica, Rev. Geophys., 26, 3, 551-578, 1988.

Hoppe, U.-P., Blix, T. A., Thrane, E. V., Lubken, F. J., Cho, J. Y. N., and Schwartz, W. E.: Studies of Polar Mesospheric Summer Echoes by VHF Radar and Rocket Probes, Adv. Space Res., 14, 9, 9139-9148, 1994.

McRae, W. M. and Thomson, N. R.: VLF phase and amplitude: daytime ionospheric parameters, J. Atmos. Sol. Terr. Phys., 62, 7, 609-618, 2000.

Morfitt, D. G. and Shellman, C. H.: MODESRCH, an Improved Computer Program for Obtaining ELF/VLF/LF Mode Constants, Naval Electronics Lab Centre Interim Report 771, NTIS Accession No. ADA032573, National Technical Information Service, Va. 22161, USA, 1976.

Murphy, D. J. and Vincent, R. A.: Amplitude Enhancements in Antarctic MF Radar Echoes, J. Geophys. Res., 105, D21, 26 683-26 693, 2000.

Nunn, D.: On the Numerical modelling of the VLF Trimpi Effect, J. of Atmospheric and Terrestrial Phys., 59, 5, 537-560, 1997.

Nunn, D. and Strangeways, H. J.: Trimpi Perturbations from Large ionisation Enhancement Patches, J. of Atmospheric and SolarTerrestrial Phys., 62, 189-206, 2000.

Palmer, J. R., Rishbeth, H., Jones, G. O. L., and Williams, P. J. S.: A Statistical Study of Polar Mesospheric Summer Echoes observed by EISCAT, J. Atmospheric and Terrestrial Physics, 58, 1-4, 307-315, 1996.

Pappert, R. A. and Hitney, L.R.: Empirical modeling of nighttime easterly and westerly VLF propagation in the Earth-ionosphere waveguide. Radio Sci., 23, 599-611, 1988.

Pfaff R., Holzworth, R., Goldberg, R., Freudenreich, H., Voss, H., Croskey, C., Mitchell, J., Gumbel, J., Bounds, S., Singer, W., and Latteck, R.: Rocket probe observations of electric field irregularities in the polar summer mesosphere, Geophys. Res. Letters, 28, 8, 1431-1434, 2001. 
Poulsen, W. L., Bell, T. F., and Inan, U. S.: Three dimensional modelling of subionospheric VLF propagation in the presence of localised D-region perturbations associated with lightning, J. Geophys. Res., 95, 3, 2355-2366, 1990.

Poulsen, W. L., Inan, U. S., and Bell, T. F.: A Multiple Mode Three Dimensional Model of VLF Propagation in the Earth ionosphere Waveguide in the Presence of Localised D-Region Disturbances, J. Geophysical Res., 98, A2, 1705-1717, 1993.

Rapp, M., Gumbel, J., Lubken, F. J., and Latteck, R.: D-Region Electron Number Density limits for the Existence of Polar Mesospheric Summer Echoes, J. Geophys. Res., 107, 14, 4187, 2002.

Rodger, C. J. and Nunn, D.: VLF Scattering from Red Sprites, Application of Numerical Modelling, Radio Science, 34, 4, 923932, 1999.

Rodger, C. J.: Subionospheric VLF perturbations associated with lightning discharges, J. Atmos. Sol. Terr. Phys., 65, 591-606, 2003.
Taylor, M. J., Vaneyken, A. P., Rishbeth, H., Witt, G., Witt, N., and Clilverd, M. A.: Simultaneous observations of noctilucent clouds and polar mesospheric radar echoes - evidence of noncorrelation, Planetary and Space Science, 37, 8, 1013-1020, 1989.

Thomas, G. E.: Mesospheric Clouds and the Physics of the Mesopause Region, Rev. Geophys., 29, 4, 553-575, 1991.

Thomson, N. R.: Experimental daytime VLF ionospheric parameters, J. Atmos. Terr. Phys., 55, 173-184, 1993.

Ulwick, J. C., Baker, K. D., Kelley, M. C., Balsley, B. B., and Ecklund, W. L.: Comparison of Simultaneous MST Radar and Electron Density probe Measurements during STATE, J. Geophys. Res., 93, 6989-7000, 1988.

Wait, J. R.: Influence of a Circular Ionospheric Depression on VLF Propagation, Radio Science, 68, D8, 907-914, 1964.

Wait, J. R.: Electromagnetic Waves in Stratified Media, corrected reprinting of 1962 edition, IEEE Press, New York, 1996.

Wait, J. R. and Spies, K. P.: Characteristics of the Earth-ionosphere Waveguide for VLF Radio Waves, NBS Tech. Note, 300, 1964. 